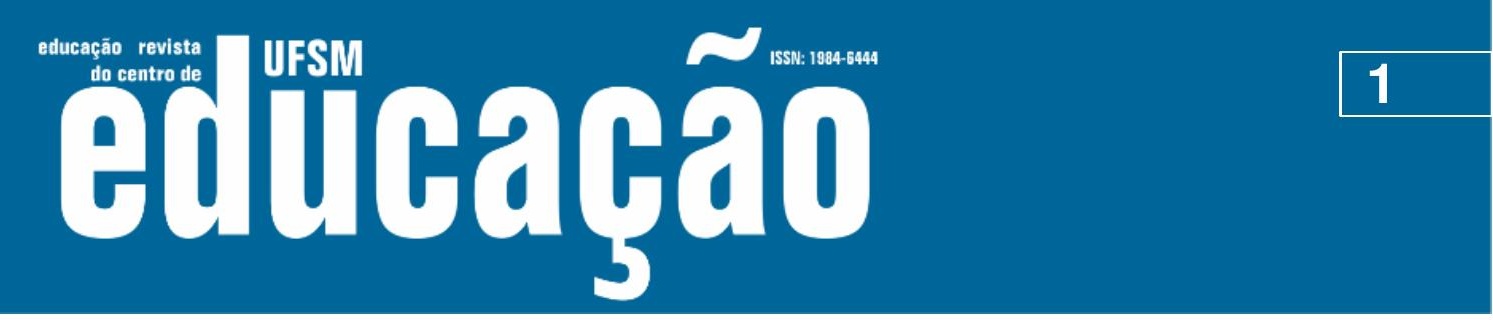

ISSN: 1984-6444 | http://dx.doi.org/10.5902/1984644431856

\title{
Construção das Políticas de Educação de Jovens e Adultos em Pernambuco: qual a racionalidade?
}

\author{
Construction of Education Policies for Youths and Adults in Pernambuco: \\ what is the rationality?
}

\section{Ana Claudia Dantas Cavalcanti}

Doutora em Educação pela Universidade Federal de Pernambuco, Nazaré da Mata, Pernambuco, Brasil.

Endereço: Universidade de Pernambuco, Faculdade de Formação de Professores de Nazaré da Mata - FFPNM. Rua Amaro Maltês de Farias s/n - Nazaré da Mata. CEP: 55800000. Nazaré da Mata, Pernambuco, Brasil.

E-mail: ana.dantas@upe.br

Recebido em 27 de março de 2018

Aprovado em 24 de dezembro de 2018

\section{RESUMO}

Este texto objetiva analisar em que medida a participação cidadã, no campo da racionalidade dialógica, permeou a construção coletiva das políticas públicas de educação de jovens e adultos, no período 2012-2015 em Pernambuco. Adota referencial teórico que considera o cidadão no campo da racionalidade dialógica. $A$ pesquisa utiliza a metodologia qualitativa e apresenta, como fonte de coleta de dados, entrevistas semiestruturada envolvendo profissionais da educação. A apreciação dos dados utiliza-se da análise de conteúdo de Bardin (1977). Os resultados indicam que as políticas públicas de educação de jovens e de adultos orientam-se por uma lógica gerencialista, o que enfraquece as possibilidades de diálogo e da participação (HABERMAS, 2012). A despeito do enfraquecimento da participação, os sujeitos deste campo, por vezes, usam a autonomia na tentativa de reverter a lógica dominante.

Palavras-chave: Educação de Jovens e Adultos; Participação cidadã; Estado gerencial.

\section{ABSTRACT}

This paper aims to analyze how citizen participation, in the field of dialogic rationality, permeated the collective construction of public policies for youths and adults education, in the period 2012-2015 in Pernambuco. It adopts a theoretical framework 


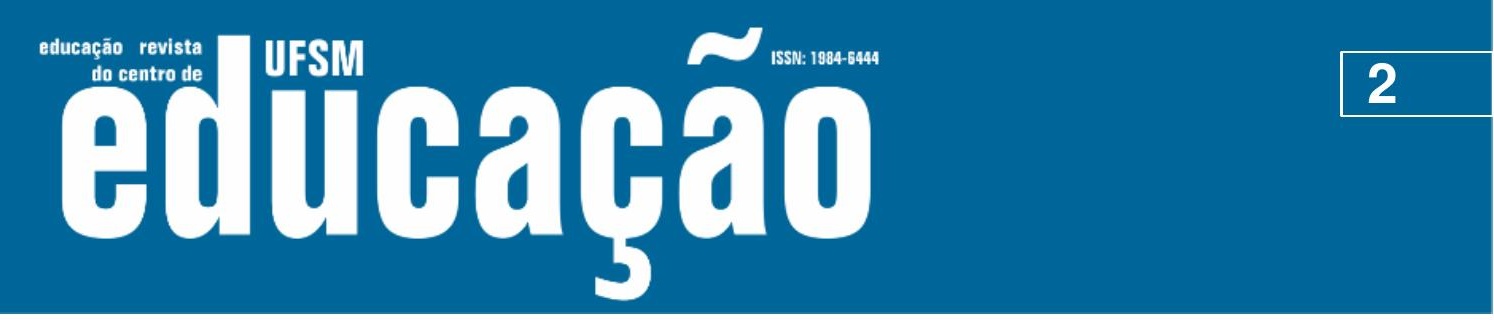

ISSN: 1984-6444 | http://dx.doi.org/10.5902/1984644431856

that considers the citizen in the field of dialogical rationality. This research uses the qualitative methodology and presentes, as source of data collection, semistructured interviews involving education professionals. The evaluation of the data is based on the content analysis of Bardin (1977). The results indicate that the public policies for youth and adult education are guided by a managerialist logic, which weakens the possibilities for dialogue and participation (HABERMAS, 2012). Despite the weakening of participation, subjects in this field, sometimes, use autonomy in an attempt to reverse the dominant logic.

Keywords: Youth and Adult Education; Citizen participation; Managerial state.

\section{Introdução}

A educação de jovens e adultos - EJA é modalidade da educação oferecida pelo sistema público de educação. Sua materialidade expressa, de um lado, a ausência do atendimento universal do acesso à educação e, por outro, a realidade objetiva de sujeitos que se encontram sem alcance ao direito básico de educação por razões diversas, incorporando, a esta reflexão, a gênese do modelo de desenvolvimento capitalista, sob os efeitos da minimização da responsabilidade social do Estado frente à liberdade liberal.

O objeto de estudo, a participação cidadã, está circunscrito no campo da racionalidade dialógica. A lógica da participação cidadã, presente neste trabalho, ancora-se na teoria da racionalidade comunicativa de Habermas (2012). Sob a teoria do agir comunicativo, o autor encontrou forma de dar continuidade à crítica da razão instrumental com base em um conceito crítico de sociedade. A estrutura da linguagem cotidiana do paradigma comunicacional tratado por Habermas (2012) encontra fundamentos na intersubjetividade visando ao entendimento, ao consenso e à deliberação, em contraposição ao paradigma liberal da razão instrumental com ênfase no desempenho de ações dirigidas a determinados fins. Esta perspectiva aponta para o cidadão como agente de poder comunicacional através do qual se opera a participação cidadã. Ao adotarmos tal perspectiva, subscrevemos a emancipação como decorrência e como processo de libertação.

Como objetivo, buscamos analisar a experiência de Pernambuco no desenvolvimento da participação cidadã, no bojo da construção da política 


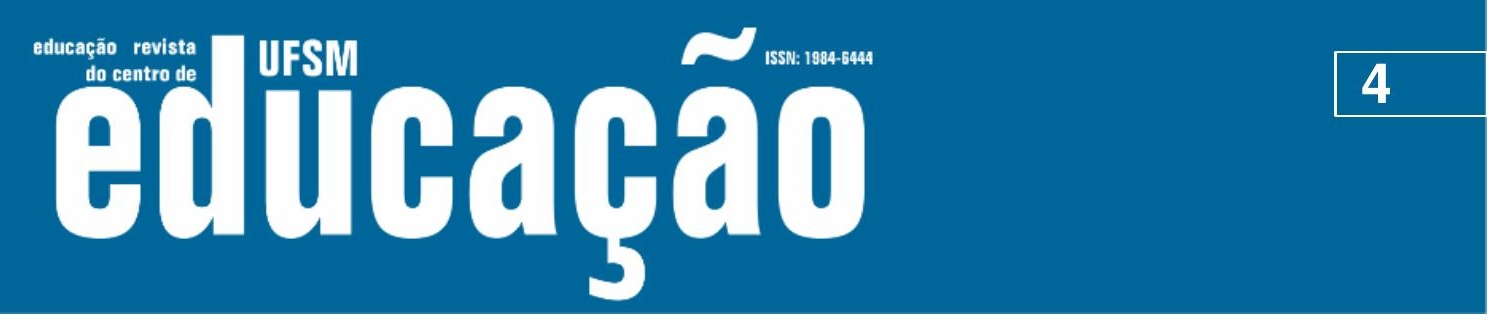

ISSN: 1984-6444 | http://dx.doi.org/10.5902/1984644431856

\section{A construção da Aprendizagem ao Longo da Vida: orientações globais de um modelo de estado em processo de legitimação}

Nos últimos dois séculos, a sociedade vivenciou e vivencia modelos administrativos de estado: o de bem-estar, o participativo e o gerencial. As políticas de educação no Brasil acompanham as orientações do Estado em seus modelos.

No estado de bem-estar, sob ação da racionalidade instrumental, a burocratização e a administração assumiram aspectos hegemônicos mediados por conhecimentos técnicos por onde os meios se justificavam na busca de determinados fins. Como contraponto à razão instrumental Habermas (2012), buscou constituir uma forma de reflexão crítica baseado na emancipação social.

A contemporaneidade está marcada pelo fenômeno da globalização e revolução tecnológica, que convivem com a competitividade e a flexibilidade do mercado sob a orientação de minimização das ações do estado. A minimização dos investimentos sociais expõe os novos princípios de regulação e participação no âmbito das relações de consumo que estiveram presentes no processo de desestruturação do Welfare State, do modelo participativo de estado e na recente estruturação do estado gerencial.

A racionalidade econômica, que, hegemonicamente, permeia as ações do estado, dispõe suas especificidades na educação e no domínio das políticas da EJA e estão expressos nos documentos da OCDE, União Europeia (UE) e UNESCO, os quais justificam a importância de investimento devido ao contributo deste domínio no desenvolvimento econômico (CAVACO, 2009). Além destas orientações, acrescemos o documento da UNESCO (1990) de Educação Para Todos, elaborado em Jomtien, que se aplica aos países signatários, a exemplo do Brasil.

Os preceitos da OCDE apresentam concepções para a democracia e livre mercado, na perspectiva da Aprendizagem ao Longo da Vida e, em sintonia com as orientações da UNESCO, foca na equidade da educação para o mercado de trabalho (OCDE, 2015). A OCDE (2015a) reconhece avanços na educação no Brasil e reforça que o país deve promover esforços adicionais para fomentar o ensino e a formação profissional, na busca por melhor modernização e para aumentar os seus níveis de qualidade com finalidades para empregabilidade e produtividade. Recomenda a 


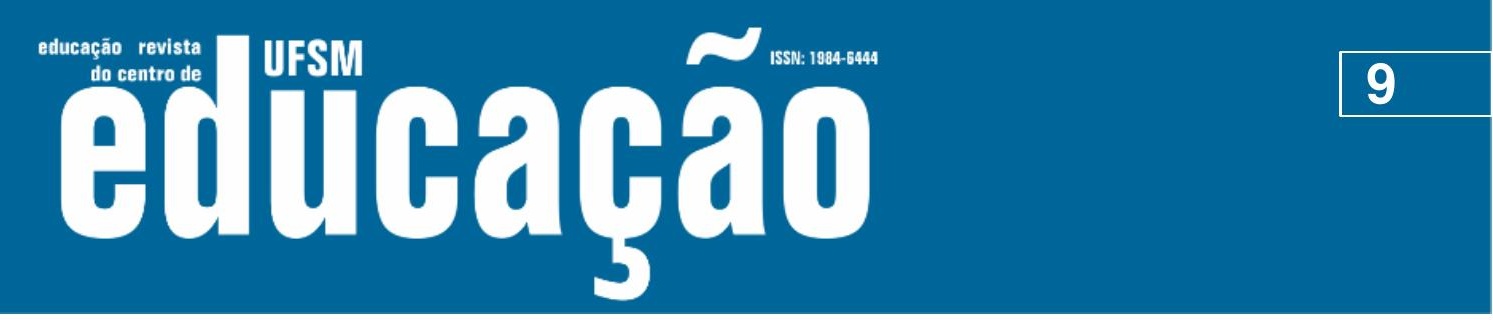

ISSN: 1984-6444 | http://dx.doi.org/10.5902/1984644431856

são expressos através do Relatório Global sobre Aprendizagem e Educação de Adultos - Global Report on Adult Learning and Education - GRALE.

O GRALE III, mais recente relatório, ofereceu planejamento para o desenvolvimento sustentável até 2030 , além de ser um instrumento de monitoramento dos compromissos assumidos pelos países subescritores. Em seus princípios, o GRALE III objetiva fortalecer a aprendizagem e a educação de adultos para os benefícios "em saúde e bem-estar, no emprego, e mercado de trabalho, vida social, cívica e comunitária." (UNESCO, 2016, p.08). Este relatório aponta estudos que comprovam que, na Europa, a concepção de Aprendizagem ao Longo da Vida tem repercutido em benefícios econômicos para os empregadores. Tal informação colabora com a percepção sobre a finalidade da educação para o fortalecimento do mercado no bojo das pressuposições ideológicas globalizadas. Fonte do monitoramento, GRALE III identifica que $70 \%$ dos países no mundo, implementaram a política de aprendizagem e educação de adultos, sendo na América Latina e Caribe um percentual de $64 \%$. Sobre a produtividade e emprego, o relatório indica $50 \%$ dos países no mundo e 44\% para os países da América Latina e Caribe (UNESCO, 2016).

\section{Ação estratégica da Educação de Jovens e Adultos e o enfrentamento da sociedade}

A EJA, como política do estado gerencial, estimula e defende dimensões características da racionalidade econômica. Tais dimensões podem ser identificadas nos processos de desregulamentação da economia, de privatização de empresas estatais, de potencialização dos mercados, nas reformas dos sistemas de previdência social, saúde e educação e de descentralização dos serviços públicos (SOUZA; FARIA, 2004). Por essa concepção de estado, a cidadania está relacionada com o valor de accountability ${ }^{5}$. Freitas (2013), ao tratar da política do accountability, elucida que a meritocracia está automaticamente envolvida nesse processo. Para Freitas

\footnotetext{
5 Palavra derivada da língua inglesa, que pode ser entendida por responsabilização ou prestação de contas. Na concepção gerencial de estado, este termo possibilita coerência ideológica no contexto organizacional de regulação e de governança, que se inovam com suporte no planejamento estratégico e avaliação.
} 


\section{Tism \\ ISSN: 1984-6444

ISSN: 1984-6444 | http://dx.doi.org/10.5902/1984644431856

Consideramos que os fóruns EJA podem constituir um mecanismo de "reinvenção da emancipação social" (SANTOS, 2007), desde que consigam assegurar a participação democrática de todos os interessados e usar estratégias de influência junto aos poderes políticos, quebrando, portanto, orientações sistêmicas no campo das estruturas reguladas pelo Estado.

A participação cidadã se materializa através do diálogo argumentada por Habermas (2012) e impõe ações derivadas da intersubjetividade dos sujeitos que comunicam, configurando o potencial gerador da realidade social. Freire (2002) reforça a tese do diálogo como lugar de alteridade, no qual os homens encontram-se e pronunciam o mundo, para transformá-lo. As teorias Freireana e Habermaseana evidenciam a importância da dimensão do diálogo. A educação libertadora e 0 agir comunicativo, na razão dos seus argumentos, reiteram a importância da subjetividade, da intersubjetividade e do conhecimento.

A leitura do mundo, da palavra, a problematização, o diálogo, a participação, a relação com o saber e a ética são dimensões que a expressão freireana recomenda para interpretarmos o ato político do educar.

A comunicação interpessoal é, para Habermas (2012), instrumento que possibilita a emancipação dos sujeitos. Nesse contexto, em que há uma forte tendência para a racionalidade econômica nos marcos do capital, a qual coloniza o mundo de vida e age para neutralizar o indivíduo, é importante a ação dos sujeitos no enfrentamento das questões que se apresentam.

Cavalcanti (2017, p.871) pondera que:

[...] a construção de um novo paradigma com aporte na teoria habermasiana requer um agir com base na igualdade de conhecimento, a fim de reconstruir uma cultura política que resulte na liberdade, mas não essa do mercado, mas na liberdade de poder decidir coletivamente a partir da racionalidade comunicativa.

O agir comunicativo dos cidadãos é mudança e corporiza uma expressão de Paulo Freire, que afirma a dificuldade de mudar, mas entende sua necessidade e urgência. O exercício da participação cidadã poderá vir a ser um fio condutor de processos dialógicos orientados para a emancipação e para a consolidação de espaço público da educação (NÓVOA, 2002), conduzindo à reversão da lógica dominante 


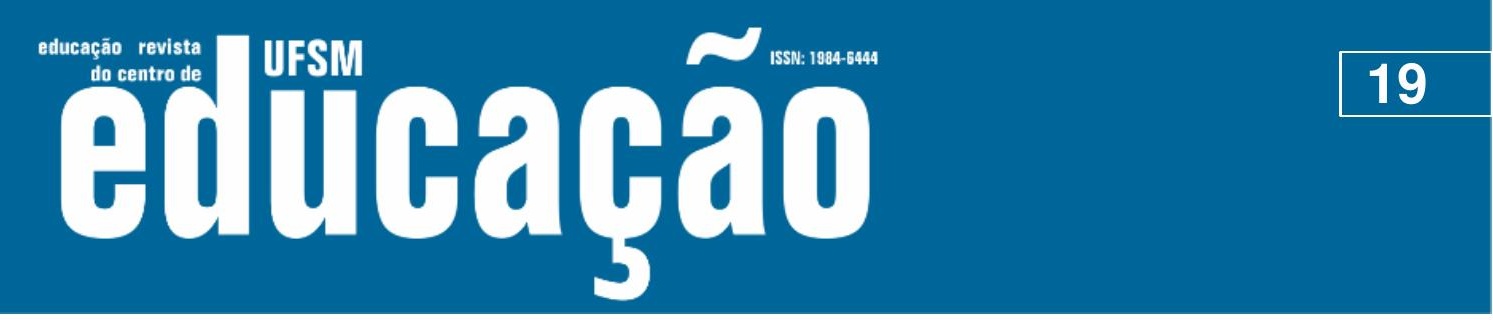

ISSN: 1984-6444 | http://dx.doi.org/10.5902/1984644431856

A participação técnico-instrumental da lógica produtiva fragiliza a EJA quando reforça uma Aprendizagem ao Longo da Vida delineada por competências a serem desenvolvidas no mercado. Nesse sentido, as políticas da EJA, no período analisado, evidenciam forte construção sistêmica inibindo a participação cidadã no campo da racionalidade dialógica. A regulação do Estado é replicada nos espaços educativos locais e os sujeitos, por vezes, exercem de autonomia para reivindicar espaços de ação.

\section{Referências}

ALVES, Natália et al. Pensar a Educação. Aprender sempre. Educação da população adulta para a cidadania participativa e responsável. Lisboa, 2014. Disponível em: http://fundacaobetania.org/ges/Educacao2015/PENSAR_A_EDUCACAO_EDUCACAO_DE_\%20A DULTOS.pdf. Acesso em: 01.08.2017.

BARDIN, Laurence. Análise de conteúdo. Lisboa: Edições 70, 1977.

BRASIL. Ministério da Educação. Planejando a Próxima Década. Conhecendo as 20 metas do Plano Nacional de Educação. Brasília, DF, 2014. 62p.

BRASIL. MEC. INEP. Censo Escolar. Notas Estatísticas. Brasília, 2016. Disponível em:

http://download.inep.gov.br/educacao_basica/censo_escolar/notas_estatisticas/2017 /notas_estatisticas_censo_escolar_da_educacao_basica_2016.pdf Acesso em 11.03.2018

BRASIL. MEC. INEP. Censo Escolar de Educação Básica. Notas Estatísticas. Brasília, 2017.

BRASIL. Lei oㅜ 13.632 de 06 de março de 2018. Altera a Lei 9.394/96 para dispor sobre educação e aprendizagem ao longo da vida. Disponível em:

http://www2.camara.leg.br/legin/fed/lei/2018/lei-13632-6-marco-2018-786231publicacaooriginal-154957-pl.html Acesso em: 20.03.2018.

CAVACO, Cármen. Adultos Pouco Escolarizados. Diversidade e Interdependência de lógica na formação. 2008. 652f. Tese (Doutoramento em Ciências da Educação - Formação de Adultos). Universidade de Lisboa: Portugal, 2008.

CAVACO, Cármen. Adultos pouco escolarizados. Políticas e práticas de formação. Lisboa: EDUCA/UI\&DCE, 2009.

CAVALCANTI, Ana Claudia D. Participação Cidadã no Contexto da Reforma Administrativa do Estado de Pernambuco. 2015. 259f. Tese (Doutoramento em Educação) - UFPE: Recife, 2015. 


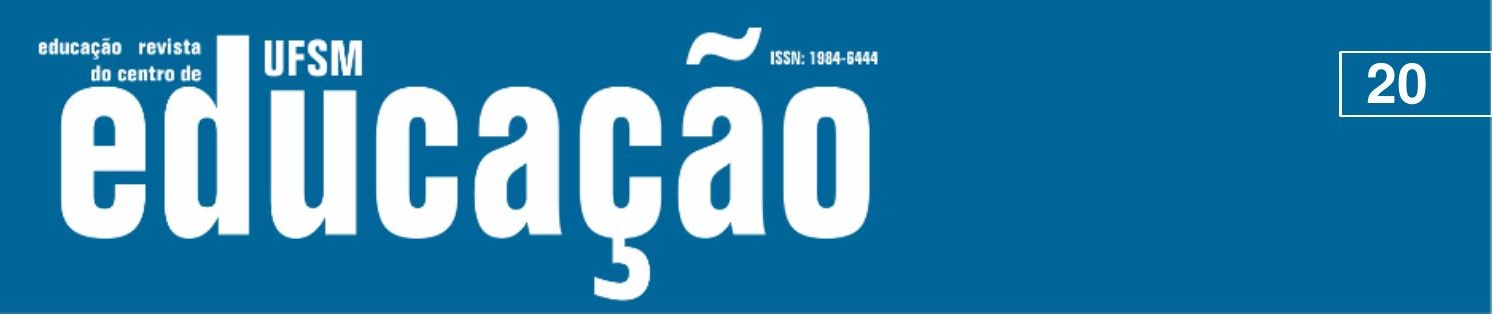

ISSN: 1984-6444 | http://dx.doi.org/10.5902/1984644431856

CAVAlCANTI, Ana Claudia D. Políticas Públicas e Participação Cidadã no Brasil: uma análise do Governo de Pernambuco. In: Correia, Luís Grosso; Leão, Ruth; Poças, Sara (ed.) (2017). O Tempo dos Professores. Porto: ClIE - Centro de Investigação e Intervenção Educativas / Faculdade de Psicologia e de Ciências da Educação da Universidade do Porto.

DALE, Roger. Globalização e educação: demonstrando a existência de uma "cultura educacional mundial comum" ou localizando uma "agenda globalmente estruturada para a educação"? Educação e Sociedade, Volume 25, 87, 423-460. 2004. Disponível em http://www.cedes.unicamp.br. Acesso em: 08.10.2017.

ENCONTRO NACIONAL DE JOVENS E ADULTOS. ENEJA II, 2000. Disponível em:http://forumeja.org.br/sites/forumeja.org.br/files/doc_eneja_campina_grande_200 0.pdf. Acesso em: 31.07.2017.

FREIRE, Paulo. Pedagogia da autonomia: saberes necessários à prática educativa. 25. a edição. São Paulo: Paz e Terra, 2002.

FREIRE, Paulo. Pedagogia do Oprimido. 42. a edição. São Paulo, Paz e Terra, 2005.

FREITAS, Luiz Carlos de. Políticas de responsabilização: entre a falta de evidência e a ética. Cadernos de Pesquisa. V. 43 n. 148, p 348 - 365 jan/abril, 2013.

Disponível em: http://www.scielo.br/pdf/cp/v43n148/18.pdf. Acesso em: 01.08.2017.

FREITAS, Luiz Carlos de. Os Reformadores Empresariais da Educação: da Desmoralização do Magistério à Destruição do Sistema Público de Educação. Educ. Soc., Campinas, v. 33, n. 119, p. 379-404, abr.-jun. 2012. Disponível em: http://www.cdn.ueg.br/arquivos/desenvolvimento_curricular_134/conteudoN/2673/Te xto_-_REFORMADORES_EMPRESARIAIS_E_EDUCACA0.pdf. Acesso em: 01.08.2017.

GALVÃO, Ana Maria de Oliveira; DI PIERRO, Maria Clara. Preconceito Conta o Analfabeto. São Paulo: Cortez, 2007.

HABERMAS, Jürgen. Teoria do Agir Comunicativo. Racionalidade da ação e racionalização social. Vol. 1. Traduzido por Paulo Astor Soethe. Sobre a crítica da razão funcionalista. Vol II. Traduzido por Flávio B. Siebeneichler. São Paulo: WMF Matins Fontes, 2012.

HABERMAS, Jürgen. Direito e democracia: entre facticidade e validade. v. I. Tradução de Flávio Beno Siebeneichler. Rio de Janeiro: Tempo Brasileiro, 2012a.

HABERMAS, Jürgen. A Ética da Discussão e a Questão da Verdade. Tradução de Marcelo Brandão Cipolla. São Paulo: Martins Fontes, 2007.

NAZARIO, Maria Ana; SANTOS, Ana Lúcia Félix. Política para Educação de Jovens e Adultos: Municipalização e Regime de colaboração. In: XXVI SIMPOSIO BRASILEIRO DE POLÍTICA E ADMINISTRAÇÃO ESCOLAR, 2013, RECIFE-PE. Cadernos ANPAE, 2013. v. 17. p. 1-13. 


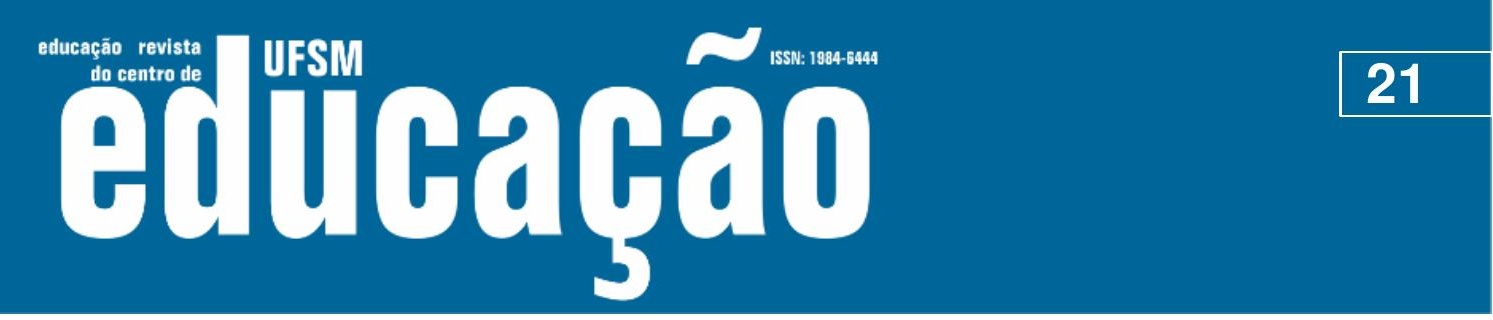

ISSN: 1984-6444 | http://dx.doi.org/10.5902/1984644431856

NÓVOA, António. O Espaço Público da Educação: Imagens, Narrativas e Dilemas. IN: NÓVOA. A. et al. Espaços de Educação, tempos de formação (pp. 237-263). Lisboa: Fundação Calouste Gulbenkian, 2002.

NÓVOA, António e RODRIGUES, Cristina. "Prefácio”. In Canário, R. e Cabrito, B. (Orgs). Educação e Formação de Adultos. Mutações e convergências (pp.7-14). Lisboa: Educa, 2005.

OCDE - "Brazil", In: Education at a Glance 2015: OECD Indicators, OECD Publishing All rights reserved, 2015. Disponível em:

https://www.oecd.org/brazil/Education-at-a-glance-2015-Brazil-in-Portuguese.pdf. Acesso em 30.07.2017.

OCDE. Brazil Policy Brief, 2015a. Disponível em: https://www.oecd.org/policybriefs/brasil-capacitacao-e-educacao-para-o-crescimento.pdf. Acesso em: 30.07.2017.

OCDE. Relatórios Econômicos da OCDE Brasil, 2015b. Disponível em: http://www.oecd.org/eco/surveys/Brasil-2015-resumo.pdf. Acesso em: 30.07.2017.

OLIVEIRA, Dalila Andrade. As políticas educacionais no governo Lula: rupturas e permanências. Revista Brasileira de Política e Administração da Educação (RBPAE), Porto Alegre, v. 25, n. 2, p. 197-209, mai./ago. 2009.

OLIVEIRA, Maria Ângela Alves. A materialização da integração entre a qualificação profissional e a formação geral no âmbito do ProJovem em Recife-PE. 2009. 195 f. Dissertação (Mestrado em Educação) - Centro de Educação, Universidade Federal de Pernambuco, Recife.

PERNAMBUCO. Secretaria Executiva de Desenvolvimento da Educação. Diretrizes Operacionais para a oferta de Educação de Jovens e Adultos. 2016. Recife, PE, 2016. 91p.

SANTOS, Boaventura Sousa. Renovar a Teoria Crítica e Reinventar a Emancipação Social. São Paulo: Boitempo Editorial, 2007.

SOUZA, Donaldo Bello de; FARIA, Lia Ciomar Macedo de. Políticas de financiamento da educação municipal no Brasil (1996-2002): das disposições legais equalizadoras às práticas político-institucionais excludentes. Ensaio: avaliação e políticas públicas em educação, Rio de Janeiro, v. 12, n. 42, p. 564-582, jan./mar. 2004.

SOUZA, João Francisco de. Educação Popular e Movimentos Sociais no Brasil. In: CANÁRIO, Rui et al (org). Educação Popular e Movimentos Sociais. Lisboa, Educa, 2007.

UNESCO - United Nations Educational, Scientific and Cultural Organisation. Conferência Mundial da Educação para Todos. Declaração mundial sobre educação para todos. Satisfação das necessidades básicas de aprendizagem. Jomtien, 1990. Disponível em: < http://unesdoc.unesco.org/images/0008/000862/086291por.pdf > Acesso em: 30/07/2017. 


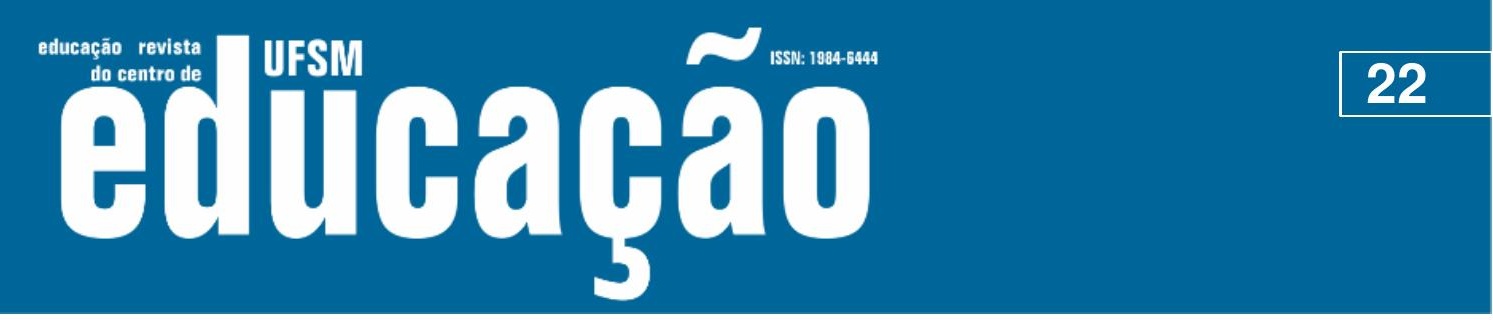

ISSN: 1984-6444 | http://dx.doi.org/10.5902/1984644431856

UNESCO. Declaração de Nova Delhi sobre Educação para Todos, 1993. Disponível em: http://unesdoc.unesco.org/images/0013/001393/139393por.pdf. Acesso em: 30.07.2017.

UNESCO. Educação Para Todos. Declaração de Cochabamba, 2001. Disponível em:

http://unesdoc.unesco.org/images/0012/001275/127510por.pdf. Acesso em: 30.07.2017.

UNESCO. O que é? O que faz? 2007. Disponível em: http://unesdoc.unesco.org/images/0014/001473/147330por.pdf. Acesso em 30.07.2017.

UNESCO. Recomendações Sobre Aprendizagem e Educação de Adultos, 2015. Disponível em: http://www.unesco.org/new/pt/brasilia/about-this-office/singleview/news/recommendation_on_adult_learning_and_education_2015_in_port/. Acesso: 01.08.2017.

UNESCO. Marco de Ação de Belém. Aproveitando o poder e o potencial da aprendizagem e educação de adultos para um futuro viável. Resumo Executivo. Brasília, agosto, 2010. Disponível em: http://www.ceeja.ufscar.br/resumo-executivo. Acesso em: 10.03.2018.

UNESCO. 3 Relatório Geral sobre Aprendizagem e Educação de Adultos. Brasília, UNESCO, 2016. Disponível em:

http://unesdoc.unesco.org/images/0024/002470/247056por.pdf. Acesso em: 10.03.2018.

UNIÃO EUROPEIA. A Educação para a Cidadania na Europa, 2012. Disponível em:

http://eacea.ec.europa.eu/education/eurydice/documents/thematic_reports/139PT.pd f. Acesso em: 30.07.2017.

UNIÃO EUROPEIA. Educação e Formação na Europa: Sistemas diferentes: objectivos comuns para 2010. Comissão Europeia. Direcção-Geral da Educação e da Cultura. Luxemburgo: Serviço das Publicações Oficiais das Comunidades Europeias, 2002.

WOOD, Ellen Meiksins. O império do capital. São Paulo: Boitempo, 2014.

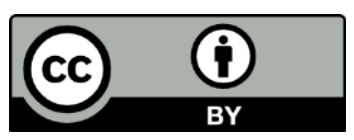

This work is licensed under a Creative Commons Attribution 4.0 International (CC BY 4.0). 